OPEN ACCESS

Edited by: Ashfaq Shuaib, University of Alberta, Canada

Reviewed by: Marco Pasi,

Massachusetts General Hospital, United States

Maxime Gauberti, INSERM, France

Martin Ebinger,

Charité Universitätsmedizin

Berlin, Germany

*Correspondence:

David Tanne

david.tanne@sheba.health.gov.il

${ }^{\dagger}$ Joint first authors.

Specialty section:

This article was submitted

to Stroke,

a section of the journal

Frontiers in Neurology

Received: 27 May 2017 Accepted: 03 August 2017 Published: 21 August 2017

Citation:

Lutski M, Zucker I, Shohat T and Tanne D (2017) Characteristics and Outcomes of Young Patients with First-Ever Ischemic Stroke

Compared to Older Patients:

The National Acute Stroke ISraeli Registry.

Front. Neurol. 8:421.

doi: 10.3389/fneur.2017.00421

\section{Characteristics and Outcomes of Young Patients with First-Ever Ischemic Stroke Compared to Older Patients: The National Acute Stroke ISraeli Registry}

\author{
Miri Lutski ${ }^{1 \dagger}$, Inbar Zucker ${ }^{1,2 t}$, Tamy Shohat ${ }^{1,2}$ and David Tanne ${ }^{2,3 *}$ \\ ${ }^{1}$ The Israel Center for Disease Control, Ministry of Health, Ramat Gan, Israel, ${ }^{2}$ Department of Epidemiology and Preventive \\ Medicine, School of Public Health, Sackler Faculty of Medicine, Tel Aviv University, Tel-Aviv, Israel, ${ }^{3}$ The Sagol Neuroscience \\ Center, Sheba Medical Center, Tel-Hashomer, Israel
}

Background: Nationwide data on the clinical profile and outcomes of ischemic stroke in younger adults are still scarce. Our aim was to analyze clinical characteristics and outcomes of young patients with first-ever ischemic stroke compared to older patients.

Methods: The National Acute Stroke ISraeli registry is a nationwide prospective hospital-based study performed triennially. Younger adults, aged 50 years and younger, were compared with patients, aged 51-84 years regarding risk factors, clinical presentation, stroke severity, stroke etiology, and outcomes. A logistic model for stroke outcome was fitted for each age group.

Results: 336 first-ever ischemic strokes were identified among patients aged 50 years and younger and 3,243 among patients 51-84 years. Younger adults had lower rates of traditional vascular risk factors, but $82.7 \%$ had at least one of these risk factors. Younger adults were more likely to be male (62.8\%), current smokers (47.3\%), and to have a family history of stroke (7.4\%). They tended to have less common stroke presentation such as sensory disturbances or headache and were more likely to arrive at the hospital independently by car. The majority of young adults (70\%) had a favorable outcome (modified Ranking Scale; $\mathrm{mRS} \leq 1$ ) at discharge, but $11.7 \%$ had poor outcome (mRS > 3) and $18.2 \%$ had an in-hospital complication. According to a multivariable regression model, in young adults, only baseline stroke severity (National Institute of Health Stroke Scale $>5$ ) was associated with poor outcome at discharge $(p<0.001)$, whereas in older adults, stroke severity $(p<0.001)$, female gender $(\mathrm{OR}=1.35, \mathrm{Cl} 95 \%$ 1.03-1.76), older age (OR $=1.08, \mathrm{Cl} 95 \% 1.01-1.16)$, atrial fibrillation $(\mathrm{OR}=1.62 \mathrm{Cl} 95 \% 1.16-2.26)$, and anterior circulation territory $(\mathrm{OR}=2.10$, Cl 95\% 1.50-2.94) were all significantly associated with poor outcome.

Conclusion: Our findings, in this nationwide registry, demonstrate the relatively high rate of smoking and family history of stroke, and the lower rate of hospital arrival by ambulance among young adults. This calls for increasing awareness to the possibility of stroke among young adults and for better prevention, especially smoking cessation.

Keywords: adults under age $\mathbf{5 0}$ years, first-ever ischemic stroke, epidemiology of stroke, outcomes of stroke, stroke, stroke registry 


\section{INTRODUCTION}

Stroke in younger adults is less frequent than in older people; however, its health and economic impact on younger individuals, their family, and society is major (1). The incidence rates of ischemic stroke in younger adults vary from 6.6 to 11.4 in 100,000 people per year (1). Incidence rates of ischemic stroke have increased in adults aged 55 years and under in the United States $(2)$ and in Europe $(3,4)$. This trend could reflect changes in the burden of classical vascular risk factors in younger individuals, such as increases in prevalences of diabetes, obesity, and hypercholesterolemia or result from the interplay of other risk factors (3).

Associations between risk factors for acute ischemic stroke and clinical outcomes have been analyzed predominantly in older rather than younger patients (5-10). However, the knowledge gleaned from research of older adults cannot always be applied to younger adults $(11,12)$. Previous studies showed that both younger and older age stroke patients shared the same modifiable risk factors (11). However, the prevalence of these risk factors was different in these two age groups $(1,11)$. Risk factors for atherosclerosis such as dyslipidemia, hypertension, and diabetes were less frequent among young stroke patients aged 40 and under, whereas other risk factors such as family history, coagulation disorders, patent foramen ovale and nonatherosclerotic vasculopathies were more frequent $(1,13)$.

A previous study from the National Acute Stroke ISraeli (NASIS) registry found major differences between the clinical characteristics and outcomes of the very elderly (aged $\geq 85$ years) patients with first-ever ischemic stroke (14); therefore, the comparison group used in this study was defined as patients aged 51-84. The purpose of our study was to examine risk factors, clinical characteristics, and in-hospital outcomes of younger adults (aged $\leq 50$ years) compared to patients 51-84 years old, with first-ever ischemic stroke in the NASIS registry.

\section{MATERIALS AND METHODS}

\section{Study Design and Population}

National Acute Stroke ISraeli is a prospective hospital-based nationwide registry performed triennially (15). Data were collected prospectively by coordinating physicians for all consecutive cases of acute cerebrovascular diseases hospitalized during 2-month periods in 2004, 2007, 2010, and 2013 at all general hospitals in Israel. The NASIS registry was approved by the ethical committees of all participating hospitals.

\section{Data Collection}

The registry was previously described in detail (15). In brief, for the NASIS registry, a specially designed structured form was used to collect data, including demographics, risk factors, comorbidities, stroke characteristics, in-hospital management, and in-hospital outcome. Stroke severity was determined using the National Institute of Health Stroke Scale (NIHSS) score (16). The modified Ranking Scale (mRS) (17) was used for assessing disability before stroke and at discharge. The TOAST classification was used to define the etiology of stroke based on in-hospital investigation (18). Prior atherosclerosis was defined as prior TIA, carotid stenosis, peripheral artery disease, or ischemic heart disease. Modifiable vascular risk factors included diabetes, dyslipidemia, smoking, hypertension, and obesity. Participants were classified into four groups: no risk factors, one, two, and three or more modifiable risk factors.

\section{Outcome Variables}

Two outcomes were studied. Poor outcome-defined as severe disability or death $(\mathrm{mRS}>3)$ at discharge; and complications during hospitalization, categorized to neurological, cardiac, infectious, and other.

\section{Statistical Analysis}

Younger adults, aged 50 years and younger, were compared with patients, aged 51-84 years regarding their baseline characteristics, stroke severity at admission, stroke etiology, and stroke outcomes.

Chi-square test was used to determine the differences between groups in the categorical variables. Continuous variables were compared using the T-test or the Mann-Whitney test. Univariate and multivariable logistic regression models were fitted separately for each age group (aged 50 years and younger and 51-84 years) to identify covariates associated with poor outcome. The registry period, age, and gender were entered in all multivariable models. Other predictors that had a level of significance of less than 0.1 in the univariate analysis were included in the final multivariable logistic regression models. Additionally, we tested for potential interactions between the predictors and no significant interactions were found. We excluded from the logistic regression models patients with prior disability $(m R S \geq 2)$ and patients with length of hospitalization of more than 1 month (approximately $1.6 \%$ among younger adults and 3.1\% among patients 51-84 years old). The analyses were performed using SPSS 23 software (SPSS Inc., Chicago, IL, USA).

\section{RESULTS}

\section{Patient Characteristics}

A total of 336 (9.4\%) first ever ischemic strokes were identified among patients aged 50 years and younger and 3,243 among patients 51-84 years (Figure 1).

Characteristics and health-related conditions of the patients, by age group, are presented in Table 1. Male gender and Arab ethnicity were significantly associated with the younger age group. Younger adults were more likely to be current smokers than were older patients ( 47.3 vs. $21.9 \%$ ) and were more likely to have a first degree relative who had a stroke before the age of 55 years (7.4 vs. $2.0 \%$ ). The younger group comprised a higher proportion of patients without vascular risk factors (17.4 vs. $5.9 \%$ ) and a lower proportion with three or more vascular risk factors (26.7 vs. $41.9 \%$ ). However, a total of $82.7 \%$ had at least one modifiable vascular risk factor.

Stroke characteristics by age group categories are presented in Table 2. The distribution of stroke etiology was significantly different between the two groups. Younger adults had a smaller 


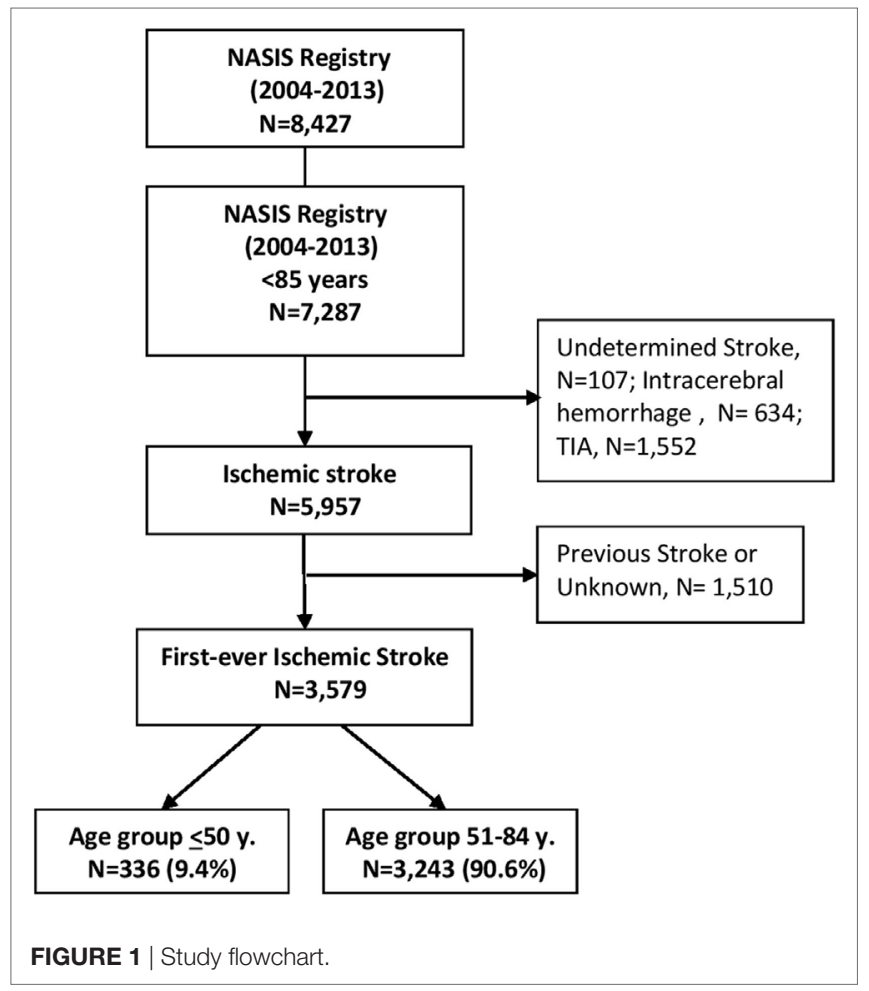

proportion of cardioembolic strokes (8.0 vs. 12.0\%) and of occlusive disease strokes (17.6 vs. $24.0 \%$ ), while strokes due to artery dissection and/or hematological disorder were more common in this group ( 6.0 vs. $0.5 \%$ ). The two age groups also differed in the clinical classification of strokes and its severity (Table 2).

The presenting symptoms of stroke by age groups are depicted in Figure 2. Motor weakness was the most frequent disturbance in both age groups. Sensory disturbances and headache were more common among younger than older patients, while speech disturbances were less common.

Only one-third (32\%) of younger adults arrived by ambulance compared to almost half (48\%) of the older patients (Table 1). Among younger patients with non-minor strokes (baseline NIHSS > 5) only $61.0 \%$ arrived by ambulance compared to $71.4 \%$ of older patients (data not shown). In both age groups, the median time elapsing from the onset of symptoms to hospital arrival (onset-to-door) and the median time elapsing from hospital arrival to undergoing CT (door-to-CT) were shorter in patients who arrived by ambulance compared to patients who arrived independently ( $2.2 \mathrm{~h}$ compared to $5.2 \mathrm{~h} ; 1.3$ and $2.3 \mathrm{~h}$, respectively) (Figures 3A,B).

\section{Stroke Outcome at Discharge}

Stroke outcome was more favorable among younger adults $(70 \%)$, with lower rates of poor outcome $(\mathrm{mRS}>3)$ at discharge (11.7\%) and lower rates of in hospital complications (18.2\%) compared to older patients (Table 3). Over the four registry periods, the rates of severe disability or death ( $\mathrm{mRS}>3$ ) declined among both groups, from $14.3 \%$ in 2004 to $5.6 \%$ in 2013 ( $p$ for trend $=0.05)$ among younger adults and from $35.5 \%$ in 2004 to $20.7 \%$ in 2013 ( $p$ for trend $<0.001$ ) among older patients
TABLE 1 | Characteristics and health-related conditions of stroke patients, by age group.

\begin{tabular}{ccc}
\multicolumn{2}{c}{ Age groups (years) } & $p$ Value \\
\cline { 2 - 2 } & $\leq 50$ & $51-84$ \\
$N=336$ & $N=3,243$ & \\
$n(\%)$ & $n(\%)$ &
\end{tabular}

p Value

\section{Demographic data}

Gender

$\begin{array}{lccc}\text { Male } & 211(62.8) & 1,833(56.5) & 0.03 \\ \text { Female } & 125(37.2) & 1,410(43.5) & \\ \text { Population group } & & & \\ \text { Jews } & 232(73.2) & 2,605(84.8) & <0.001 \\ \text { Arab } & 71(22.4) & 398(13.0) & \\ \text { Others } & 14(4.4) & 68(2.2) & \end{array}$

Known risk factors and comorbidities

Current smoking

$159(47.3) \quad 702(21.9) \quad<0.001$

Hypertension

$133(39.7) \quad 2,499(77.3) \quad<0.001$

Diabetes

Dyslipidemia

Obesity

Atrial fibrillation

76 (22.6)

$161(48.2)$

$1,410(43.5)$

$<0.001$

$2,007(62.2) \quad<0.001$

$73(22.5) \quad 644(20.9)$

$548(17.0)$

$9(2.7)$

Congestive heart failure

Chronic kidney disease

Peripheral artery disease

12 (3.6)

$14(4.2)$

7 (2.1)

(3.6) 12

391 (12.1)

$377(11.7)$

$191(5.9)$

$201(6.3)$

$79(2.5)$

Known carotid stenosis $>50 \%$

$2(0.6)$

$33(9.8)$

$24(7.4)$

$891(27.5)$

$61(2.0)$

$12(0.4)$

$18(2.8)$

14 (11.3)

$612(19.3)$

0.5

$<0.001$

$<0.001$

$<0.001$

0.004

0.05

0.03

$<0.001$

$<0.001$

$<0.001$

Known patent foramen ovale

Prior disability (modified Ranking

12 (3.6)

$<0.001$

Scale $\geq 2)$

Score of modifiable vascular risk factors

$\begin{array}{lccr}\text { No } & 56(17.4) & 181(5.9) & <0.001 \\ 1 & 90(28.0) & 628(20.6) & \\ 2 & 90(28.0) & 961(31.6) & \\ 3+ & 86(26.7) & 1,275(41.9) & \\ \text { Prior atherosclerosis } & & & \\ \text { No } & 283(85.2) & 2,053(64.5) & <0.001 \\ \text { Yes } & 49(14.8) & 1,129(35.5) & \\ \text { Medications prior to event } & & & \\ \text { Statin } & 72(21.8) & 1,389(44.0) & <0.001 \\ \text { ACE/ARB } & 61(18.5) & 1,405(44.3) & <0.001 \\ \text { Antiplatelet } & 67(20.1) & 1,513(47.8) & <0.001 \\ \text { Anticoagulants } & 15(4.5) & 276(8.7) & 0.009 \\ \text { Mode of arrival to emergency room } & & \\ \text { Ambulance } & 102(32.2) & 1,454(47.6) & <0.001 \\ \text { Private car } & 183(57.7) & 1,379(45.2) & \\ \text { Transfer from other hospital } & 17(5.4) & 43(1.4) & \\ \text { Other } & 15(4.7) & 177(5.8) & \end{array}$

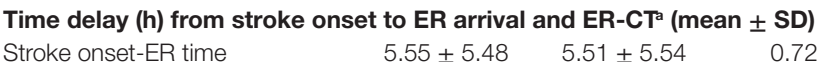

$\begin{array}{llll}\text { ER-CT time } & 3.53 \pm 4.48 & 3.39 \pm 4.53 & 0.63\end{array}$

Revascularization

$\begin{array}{llll}\text { Thrombolysis } & 17(5.1) & 159(4.9) & 0.89\end{array}$

Mechanical revascularization $\quad 8(11.1) \quad 24(3.0) \quad<0.001$

ACE/ARB, angiotensin-converting-enzyme inhibitor/angiotensin II receptor antagonists. ${ }^{a}$ Data missing for approximately $30 \%$ of cases. Patients with in-hospital events and those transferred from other hospitals excluded from analysis.

(Figures 4A,B). No significant decline was found in stroke severity distribution during the 9-year registry period among young adults ( $p$ for trend $=0.18$ ), whereas among older patient, there 
was a significant decline in severity NIHSS $>5$ during the 9-year registry period with $p$ for trend $<0.001$ (data not shown).

Multivariable logistic regression models for poor outcome were fitted separately for each age group (Table 4). The variables adjusted for in these final models were chosen according to univariate models in Table S1 in Supplementary Material.

TABLE 2 | Stroke characteristics, severity at admission, by age group.

\begin{tabular}{ccc}
\multicolumn{2}{c}{ Age groups (years) } & \\
\cline { 1 - 2 }$\leq 50$ & & \\
$N=336$ & $51-84$ & \\
$n(\%)$ & $n(\%)$ &
\end{tabular}

\begin{tabular}{lccc}
\hline Stroke etiology & & & \\
Cardioembolic & $27(8.0)$ & $390(12.0)$ & $<0.001$ \\
Large vessel occlusive disease & $22(6.5)$ & $216(6.7)$ & \\
Small vessel occlusive disease & $59(17.6)$ & $777(24.0)$ & \\
Other ${ }^{a}$ & $20(6.0)$ & $17(0.5)$ & \\
Undetermined & $203(60.4)$ & $1,815(56.0)$ & \\
Procedure related & $5(1.5)$ & $28(0.9)$ & \\
Clinical classification of ischemic stroke, $\boldsymbol{n}(\%)$ & & \\
Lacunar & $107(31.8)$ & $846(26.2)$ & \\
Total anterior circulation & $17(5.1)$ & $235(7.3)$ & \\
Partial anterior circulation & $115(34.2)$ & $1,234(38.2)$ & \\
Posterior circulation & $71(21.1)$ & $749(23.2)$ & \\
Unknown & $26(7.7)$ & $163(5.1)$ & \\
Stroke severity, $\boldsymbol{n}$ (\%) & & & \\
National Institute of Health Stroke Scale & & \\
$\leq 5$ & $242(72.2)$ & $1,933(59.7)$ & $<0.001$ \\
$6-10$ & $54(16.1)$ & $737(22.8)$ & \\
$11-15$ & $15(4.5)$ & $261(8.1)$ & \\
16-20 & $9(2.7)$ & $185(5.7)$ & \\
$>20$ & $15(4.5)$ & $121(3.7)$ & \\
Length of hospitalization & & & \\
Length (days) & $6.11 \pm 5.1$ & $6.6 \pm 5.6$ \\
\hline
\end{tabular}

${ }^{a}$ Cervical artery dissection, hematological disorder (hypercoagulability, antiphospholipid antibody syndrome, etc.).
According to multivariable regression models, stroke severity (NIHSS $>5$ ) at admission was positively associated with poor outcome (mRS $>3$ ) in both age groups (Table 4). In older patients, older age $(\mathrm{OR}=1.08$, CI 95\% 1.01-1.16), female gender $(\mathrm{OR}=1.35$, CI 95\% 1.03-1.76), atrial fibrillation $(\mathrm{OR}=1.62, \mathrm{CI}$ $95 \% 1.16-2.26)$, and anterior circulation territory $(\mathrm{OR}=2.10$, CI 95\% 1.50-2.94) were also associated with poor outcome. In younger adults, female gender $(\mathrm{OR}=2.37$, CI 95\% 0.89-6.33), posterior circulation territory $(\mathrm{OR}=4.25$, CI 95\% 0.93-19.42), and prior atherosclerosis $(\mathrm{OR}=2.89$, CI 95\% 0.91-9.18) were associated with poor outcome; however, these associations did not reach statistical significance (Table 4).

\section{DISCUSSION}

In this nationwide study, nearly half of younger adults with first-ever ischemic stroke reported current smoking. This is considerably higher than the reported prevalence of smoking among the general Israeli population aged 21-50 (21.2\%) (19). The relatively high rate of smoking among younger stroke patients highlights its significance as an important modifiable risk factor for stroke in this age group and emphasizes the need for better smoking prevention strategies that address younger adults. Similar to previous studies $(20,21)$, ischemic stroke among younger patients was more common among males.

The majority of stroke cases in younger adults were related to the existence of traditional stroke risk factors, though the prevalence of these factors was lower than in older patients; concurring with other studies (7). Two or more vascular risk factors in young adults were found in $55 \%$ of our patients, which was similar to the $52 \%$ reported in the registries of Zurich and Bern (9). This highlights the importance of these modifiable risk factors for the occurrence of stroke in all ages. Therefore, targeting these risk factors is essential for primary prevention of stroke. However, $17 \%$ of the young adults in our study had none of the classical risk factors. In these cases, other potential

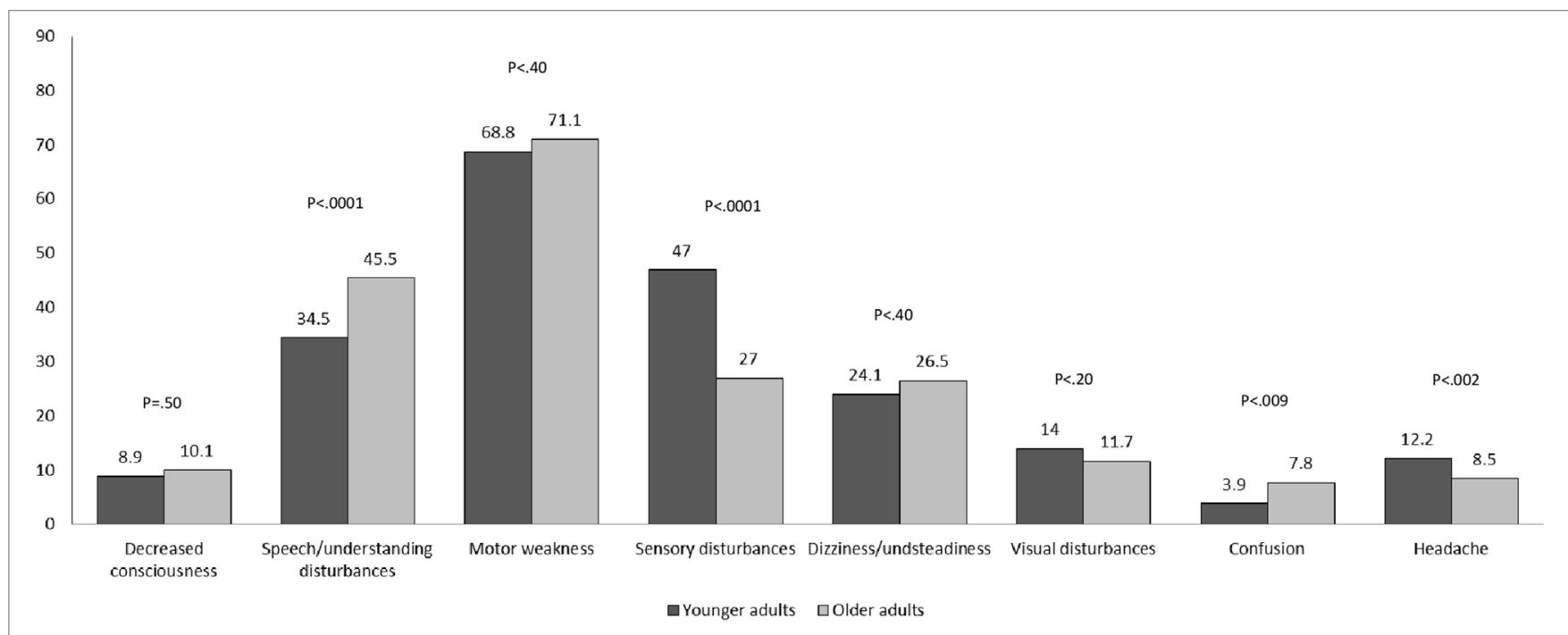

FIGURE 2 | Prevalence of presenting symptoms by age group (\%). 

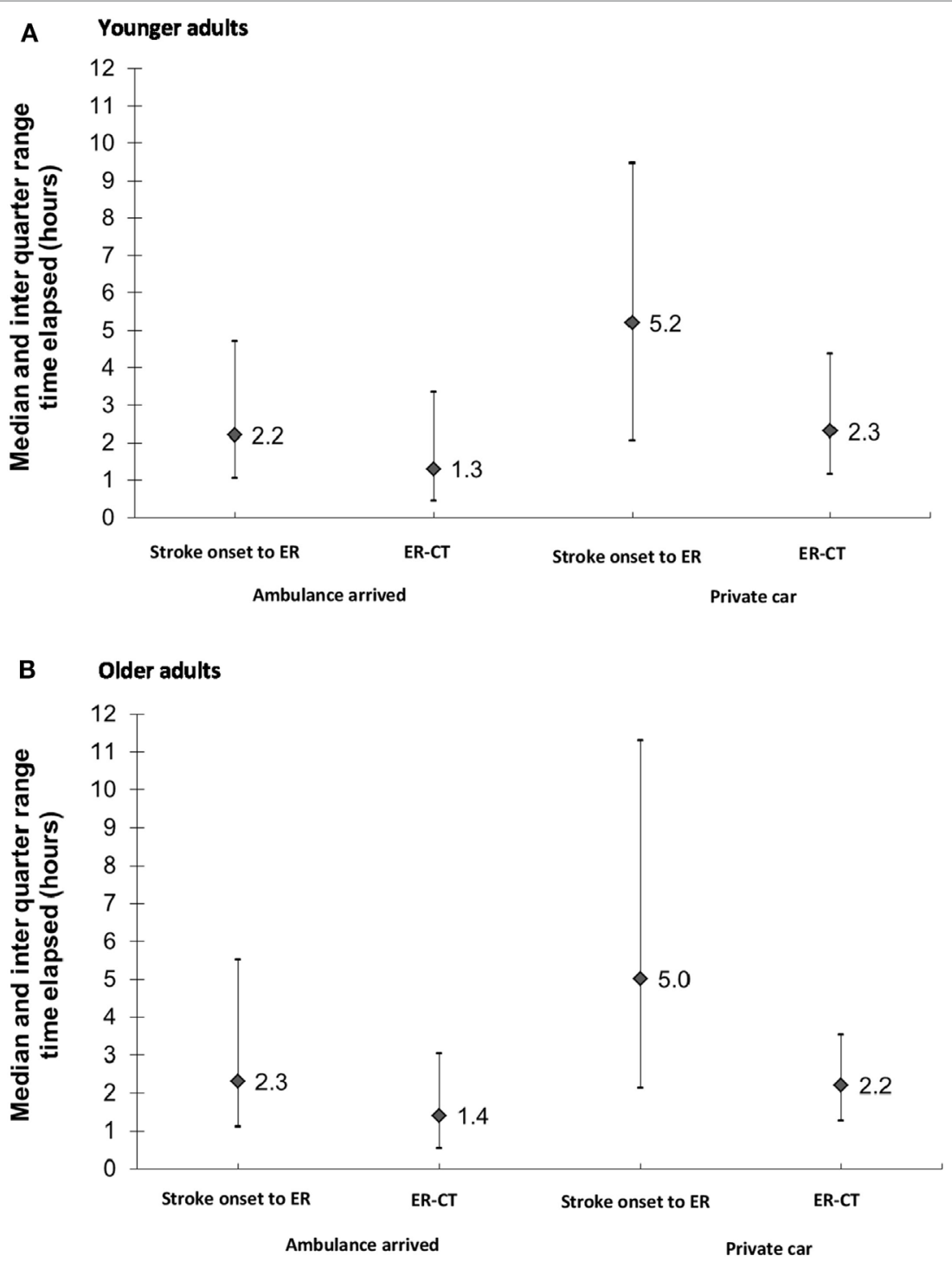

FIGURE 3 | (A,B) Time elapsed* (h) from stroke onset to ER arrival ${ }^{\star \star}$ and ER-CT by transportation arrived. (A) Younger adults and (B) older adults. *Data missing for approximately $30 \%$ of cases; ${ }^{* *}$ Patients with in-hospital events and those transferred from other hospitals were excluded from the analysis.

TABLE 3 | Outcomes of first ischemic stroke by age groups.

\begin{tabular}{|c|c|c|}
\hline \multicolumn{2}{|c|}{ Age groups (years) } & $p$ Value \\
\hline$\leq 50$ & $51-84$ & \\
\hline$N=336$ & $N=3,243$ & \\
\hline
\end{tabular}

\begin{tabular}{lrcc}
\hline In-hospital complications, $\boldsymbol{n}$ (\%) & & & \\
Neurological & $19(5.7)$ & $282(8.7)$ & 0.06 \\
Cardiac & $4(1.2)$ & $104(3.2)$ & 0.04 \\
Infectious & $27(8.0)$ & $403(12.4)$ & 0.02 \\
Bleeding & $2(0.6)$ & $53(1.6)$ & 0.04 \\
Other & $9(2.7)$ & $142(4.4)$ & 0.10
\end{tabular}

Disability at discharge and in-hospital mortality, n (\%)

Modified Ranking Scale at discharge

$0-1$

2-3

4-5

In-hospital death

$\begin{array}{ccc}235(70.1) & 1,370(42.5) & <0.001 \\ 61(18.2) & 1,013(31.4) & \\ 31(9.3) & 694(21.5) & \\ 8(2.4) & 150(4.6)\end{array}$

risk factors such as genetic coagulation disorders should be considered. Indeed, younger adults were more likely to have a family history of stroke than were older patients. This calls for increased awareness toward appropriate review of family history in younger adults.

Notably, among younger compared to older patients, first ischemic strokes were more likely to be caused by such etiologies as cervical artery dissection and hematologic disorders, and less likely by cardioembolic source. In line with previous studies, we found that in most cases of ischemic stroke in younger adults, the underlying etiology remained unclear (1). Similarly, in patients aged 15-49 years with first-ever ischemic stroke from 15 European stroke centers, the etiology remained undetermined in $40 \%$ (7). A reason for our particularly high proportion of undetermined stroke is that subtyping of stroke etiology was based only on information available at hospital discharge. In practice, 


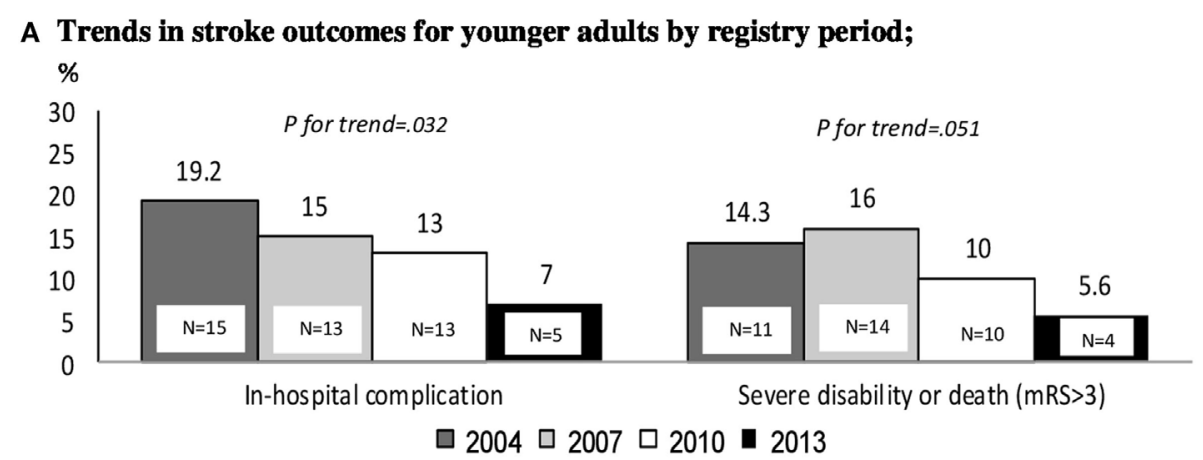

B Trends in stroke outcomes for older adults by registry period.

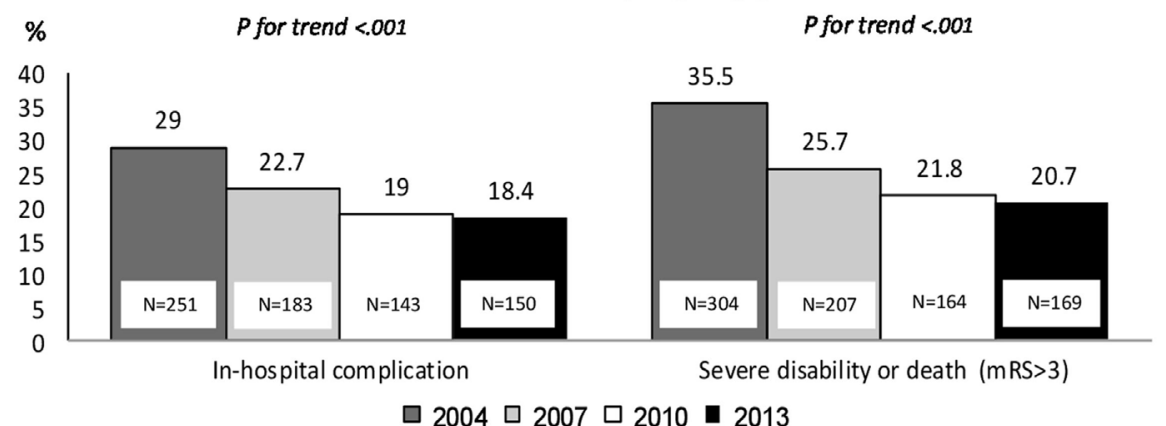

FIGURE 4 | (A,B) Trends in stroke outcomes by registry period. (A) Trends in stroke outcomes for younger adults by registry period and (B) trends in stroke outcomes for older adults by registry period.

TABLE 4 | Independent predictors of severe disability (modified Ranking Scale > 3) or in-hospital mortality by age group.

\begin{tabular}{|c|c|c|c|c|c|}
\hline & & \multicolumn{2}{|c|}{$18-50$ years } & \multicolumn{2}{|c|}{$51-84$ years } \\
\hline & & OR (95\% CI) & $p$-Value & OR $(95 \% \mathrm{Cl})$ & $p$-Value \\
\hline Age (for every increase in 5 years) & & $0.94(0.67-1.33)$ & 0.73 & $1.08(1.01-1.16)$ & 0.03 \\
\hline Female gender & & 2.37 (0.89-6.33) & 0.09 & $1.35(1.03-1.76)$ & 0.03 \\
\hline \multirow[t]{2}{*}{ National Institute of Health Stroke Scale at admission } & $>5$ & $27.38(7.79-93.15)$ & $<0.001$ & $13.04(9.67-17.60)$ & $<0.001$ \\
\hline & $\leq 5$ & ref & & ref & \\
\hline \multirow[t]{3}{*}{ Clinical subtypes of stroke } & TAC/PAC & $3.03(0.75-12.16)$ & 0.12 & $2.10(1.50-2.94)$ & $<0.001$ \\
\hline & PC & $4.25(0.93-19.42)$ & 0.06 & $1.08(0.71-1.65)$ & 0.7 \\
\hline & Lacunar & ref & & ref & \\
\hline Prior atherosclerosis & & $2.89(0.91-9.18)$ & 0.07 & $1.31(0.99-1.73)$ & 0.06 \\
\hline Atrial fibrillation & & - & & $1.62(1.16-2.26)$ & 0.005 \\
\hline Previous statin use & & - & & $0.75(0.55-1.02)$ & 0.07 \\
\hline Obesity & & - & & $1.18(0.87-1.61)$ & 0.28 \\
\hline Dyslipidemia & & - & & $1.20(0.88-1.63)$ & 0.25 \\
\hline
\end{tabular}

The models were adjusted for the registry period.

TAC/PAC, total anterior circulation/partial anterior circulation; PC, posterior circulation.

the work-up of stroke etiology is often done following discharge by diagnostic tests performed in the community.

Younger adults had a high proportion of lacunar strokes, whereas stroke of the anterior circulation was more common among older patients. This partially explains the higher proportion of mild stroke (NIHSS $\leq 5$ ) among younger adults in this study as lacunar strokes are known to be less severe $(6,9,22)$.
Younger adults with stroke were more likely to arrive to the hospital by private car than were older patients. This finding is of interest since according to our data, arrival by car was associated with longer onset-to door and door-to-CT times. Provision of timely treatment in acute stroke is critical, especially in the current era of stroke care, with the advancement of reperfusion strategies by thrombolysis and mechanical thrombectomy (21). Not 
only is early hospital arrival in acute stroke critical to reperfusion therapy but it also increases the probability of survival and affects other clinical outcomes in all patients with ischemic stroke, even when reperfusion therapy is not used (23). Possibly, the delay in hospital arrival of young adults is due to less common stroke presentation, as reported here. In addition, younger adults may have lower awareness to the possibility of stroke. In this study, motor weakness was the most frequent disturbance in both age groups; however, the proportions with sensory disturbances and headaches were higher among the younger patients. Indeed, in our study, patients with sensory disturbances or headaches were more likely to arrive by private car than were patients presenting with motor weakness, decreased consciousness, or speech disturbances.

Another important finding of this study is the substantial decline in poor stroke outcome $(\mathrm{mRS}>3$ ) among both age groups. A decline in stroke severity (NIHSS $>5$ ) during the 9 -year registry period was observed in both age group; however, only among older patients it reached statistical significance. This can be explained by improved management of known vascular risk factors such as hypertension, dyslipidemia, and diabetes mellitus (24). In addition, the growing use of reperfusion modalities may have also contributed to the improved outcomes. It should be noted that in the registry periods the use of reperfusion therapy was still limited but has been expected to grow since, especially following the publications of landmark studies that established the efficacy of mechanical revascularization $(25,26)$. The decline in the overall complication rate in both age groups during the 9-year registry period can be at least partially explained by improved acute stroke care (27). Of the factors investigated in this study, only the severity of stroke at admission was positively associated with poor outcome in younger adults. In the Zurich and Bern ischemic stroke registries, stroke of the anterior circulation, older age, and severity of stroke were associated with unfavorable outcome or death at 3 months (9), while in the Swiss Young Stroke Study, severity of stroke and diabetes were reported to predict unfavorable outcome at 3 months (8). This difference might be explained by the fact that previous studies focused on clinical outcomes at 3 months after the ischemic stroke $(8,9)$, while this study focused only on in-hospital outcomes. Yet, prior atherosclerosis, female gender, and posterior circulation territory were found to be associated with unfavorable clinical outcome among younger adults with borderline significance; this may be due to insufficient statistical power.

Our study has several methodological strengths, including its good external validity since data were obtained from a nonselective nationwide registry. In addition, our study used a validated measure of functioning, which was consistently measured at admission and at discharge. Some methodological limitations, however, should be considered. A major limitation of our study is the extremely high rate of stroke of undetermined origin, because the data collected were limited to the hospitalization period. In Israel, diagnostic tests aimed at identifying the stroke etiology (such as coagulation and genetic tests, echocardiography, Holter
ECG) is often performed in the community. Yet, other studies with the exception of three studies $(9,10,28)$ showed that despite a broad diagnostic approach and availability of accurate diagnostic tools, the proportion of stroke of undetermined etiology still remains high among young stroke patients $(7,11)$. Second, the study included only hospitalized stroke patients; and information on patients not admitted was not available. Nonetheless, there are noknown barriers for hospital admission in the Israeli health-care system. Other limitation is the absence of data on recreational drug and oral contraceptive; however, recreational drugs are a rare risk factor for stroke in young Western populations (13), and the role of oral contraceptives as a risk factor for ischemic stroke remains still controversial (12). Another limitation is the absence of data on neuroimaging features such as ischemic stroke volume and previous small vessel disease, which can affect stroke outcome. It is well known that small-vessel disease can produce small deep hemispherical or brainstem lacunar infarcts in young adults, usually in patients with vascular risk factors (12).

In conclusion, our findings, in this nationwide registry, demonstrate that young adults have high prevalence of modifiable vascular risk factors and especially a high rate of smoking. In addition, our findings demonstrate a relatively high rate of family history of stroke, and lower rate of hospital arrival by ambulance among young adults. In our study, stroke in young patients was associated with poor outcome at discharge in almost $12 \%$, and this may lead to major morbidity and long-term socioeconomic consequences. This calls for increasing awareness to the possibility of stroke among young adults and for better prevention, especially smoking cessation.

\section{ETHICS STATEMENT}

The NASIS registry was approved by the ethical committees of all participating hospitals.

\section{AUTHOR CONTRIBUTIONS}

ML, IZ, TS, and DT contributed to the design, data interpretation, and critical review. DT contributed to the data collection. ML and IZ contributed to draft the manuscript and data analysis. All authors contributed to revising the manuscript for publication and approved the final version for publication.

\section{FUNDING}

The NASIS Project was supported by the Israeli Center for Disease Control, Israeli Ministry of Health, and by MSD, Novo-Nordisk, Pfizer, Sanofi-Aventis, Rafa Laboratories, and Teva.

\section{SUPPLEMENTARY MATERIAL}

The Supplementary Material for this article can be found online at http://journal.frontiersin.org/article/10.3389/fneur.2017.00421/ full\#supplementary-material. 


\section{REFERENCES}

1. Griffiths D, Sturm J. Epidemiology and etiology of young stroke. Stroke Res Treat (2011) 2011:209370. doi:10.4061/2011/209370

2. Ramirez L, Kim-Tenser MA, Sanossian N, Cen S, Wen G, He S, et al. Trends in acute ischemic stroke hospitalizations in the United States. J Am Heart Assoc (2016) 5. doi:10.1161/JAHA.116.003233

3. Béjot Y, Delpont B, Giroud M. Rising stroke incidence in young adults: more epidemiological evidence, more questions to be answered. J Am Heart Assoc (2016) 5. doi:10.1161/JAHA.116.003661

4. Tibaek M, Dehlendorff C, Jørgensen HS, Forchhammer HB, Johnsen SP, Kammersgaard LP. Increasing incidence of hospitalization for stroke and transient ischemic attack in young adults: a registry-based study. J Am Heart Assoc (2016) 5. doi:10.1161/JAHA.115.003158

5. von Sarnowski B, Putaala J, Grittner U, Gaertner B, Schminke U, Curtze S, et al. Lifestyle risk factors for ischemic stroke and transient ischemic attack in young adults in the Stroke in Young Fabry Patients study. Stroke (2013) 44:119-25. doi:10.1161/STROKEAHA.112.665190

6. Prefasi D, Martínez-Sánchez P, Fuentes B, Díez-Tejedor E. Severity and outcomes according to stroke etiology in patients under 50 years of age with ischemic stroke. J Thromb Thrombolysis (2016) 42:272-82. doi:10.1007/ s11239-016-1336-5

7. Yesilot Barlas N, Putaala J, Waje-Andreassen U, Vassilopoulou S, Nardi K, Odier C, et al. Etiology of first-ever ischaemic stroke in European young adults: the 15 cities young stroke study. Eur J Neurol (2013) 20:1431-9. doi:10.1111/ene.12228

8. Goeggel Simonetti B, Mono ML, Huynh-Do U, Michel P, Odier C, Sztajzel R, et al. Risk factors, aetiology and outcome of ischaemic stroke in young adults: the Swiss Young Stroke Study (SYSS). J Neurol (2015) 262:2025-32. doi:10.1007/s00415-015-7805-5

9. Nedeltchev K, der Maur TA, Fischer U, Baumgartner RW, Arnold M, Caso V, et al. Ischaemic stroke in young adults: predictors of outcome and recurrence. J Neurol Neurosurg Psychiatry (2005) 76:191-5. doi:10.1136/ jnnp.2004.040543

10. Ji R, Schwamm LH, Pervez MA, Singhal AB. Ischemic stroke and transient ischemic attack in young adults: risk factors, diagnostic yield, neuroimaging, and thrombolysis. JAMA Neurol (2013) 70:51-7. doi:10.1001/ jamaneurol.2013.575

11. Smajlovic D. Strokes in young adults: epidemiology and prevention. Vasc Health Risk Manag (2015) 11:157-64. doi:10.2147/VHRM.S53203

12. Ferro JM, Massaro AR, Mas JL. Aetiological diagnosis of ischaemic stroke in young adults. Lancet Neurol (2010) 9:1085-96. doi:10.1016/ S1474-4422(10)70251-9

13. Maaijwee NA, Rutten-Jacobs LC, Schaapsmeerders P, van Dijk EJ, de Leeuw FE. Ischaemic stroke in young adults: risk factors and longterm consequences. Nat Rev Neurol (2014) 10:315-25. doi:10.1038/nrneurol. 2014.72

14. Gur AY, Tanne D, Bornstein NM, Milo R, Auriel E, Shopin L, et al. Stroke in the very elderly: characteristics and outcome in patients aged $\geq 85$ years with a first-ever ischemic stroke. Neuroepidemiology (2012) 39:57-62. doi:10.1159/000339362

15. Tanne D, Goldbourt U, Koton S, Grossman E, Koren-Morag N, Green MS, et al. A national survey of acute cerebrovascular disease in Israel: burden, management, outcome and adherence to guidelines. Isr Med Assoc J (2006) 8:3-7.

16. Wityk RJ, Pessin MS, Kaplan RF, Caplan LR. Serial assessment of acute stroke using the NIH Stroke Scale. Stroke (1994) 25:362-5. doi:10.1161/01. STR.25.2.362
17. van Swieten JC, Koudstaal PJ, Visser MC, Schouten HJ, van Gijn J. Interobserver agreement for the assessment of handicap in stroke patients. Stroke (1988) 19:604-7. doi:10.1161/01.STR.19.5.604

18. Adams HP Jr, Bendixen BH, Kappelle LJ, Biller J, Love BB, Gordon DL, et al. Classification of subtype of acute ischemic stroke. Definitions for use in a multicenter clinical trial. TOAST. Trial of Org 10172 in Acute Stroke Treatment. Stroke (1993) 24:35-41. doi:10.1161/01.STR.24.1.35

19. Karolinsky D, Enav T, Ifrah A, Keinan-Boker L, Shohat, T. Israel National Health Interview Survey INHIS-3, 2014 - Selected Findings. Israel Center for Disease Control, Ministry of Health (2016). Available from: https://www. health.gov.il/English/MinistryUnits/ICDC/Health_Surveys/Pages/INHIS. aspx

20. Putaala J, Yesilot N, Waje-Andreassen U, Pitkäniemi J, Vassilopoulou S, Nardi K, et al. Demographic and geographic vascular risk factor differences in European young adults with ischemic stroke: the 15 cities young stroke study. Stroke (2012) 43:2624-30. doi:10.1161/STROKEAHA.112.662866

21. Koton S, Telman G, Kimiagar I, Tanne D, NASIS Investigators. Gender differences in characteristics, management and outcome at discharge and three months after stroke in a national acute stroke registry. Int J Cardiol (2013) 168:4081-4. doi:10.1016/j.ijcard.2013.07.019

22. Murat Sumer M, Erturk O. Ischemic stroke subtypes: risk factors, functional outcome and recurrence. Neurol Sci (2002) 22:449-54. doi:10.1007/ s100720200004

23. Denti L, Artoni A, Scoditti U, Gatti E, Bussolati C, Ceda GP. Pre-hospital delay as determinant of ischemic stroke outcome in an Italian cohort of patients not receiving thrombolysis. JStroke Cerebrovasc Dis (2016) 25:1458-66. doi:10.1016/j.jstrokecerebrovasdis.2016.02.032

24. Meschia JF, Bushnell C, Boden-Albala B, Braun LT, Bravata DM, Chaturvedi S, et al. Guidelines for the primary prevention of stroke: a statement for healthcare professionals from the American Heart Association/ American Stroke Association. Stroke (2014) 45:3754-832. doi:10.1161/ STR.0000000000000046

25. Goyal M, Menon BK, van Zwam WH, Dippel DW, Mitchell PJ, Demchuk AM, et al. Endovascular thrombectomy after large-vessel ischaemic stroke: a meta-analysis of individual patient data from five randomised trials. Lancet (2016) 387:1723-31. doi:10.1016/S0140-6736(16)00163-X

26. Campbell BC, Mitchell PJ, Kleinig TJ, Dewey HM, Churilov L, Yassi N, et al. Endovascular therapy for ischemic stroke with perfusion-imaging selection. N Engl J Med (2015) 372:1009-18. doi:10.1056/NEJMoa1414792

27. Tanne D, Koton S, Molshazki N, Goldbourt U, Shohat T, Tsabari R, et al. Trends in management and outcome of hospitalized patients with acute stroke and transient ischemic attack: the National Acute Stroke ISraeli (NASIS) registry. Stroke (2012) 43:2136-41. doi:10.1161/STROKEAHA. 111.647610

28. Tancredi L, Martinelli Boneschi F, Braga M, Santilli I, Scaccabarozzi C, Lattuada P, et al. Stroke care in young patients. Stroke Res Treat (2013): 715380. doi:10.1155/2013/715380

Conflict of Interest Statement: The authors declare that the research was conducted in the absence of any commercial or financial relationships that could be construed as a potential conflict of interest.

Copyright $\odot 2017$ Lutski, Zucker, Shohat and Tanne. This is an open-access article distributed under the terms of the Creative Commons Attribution License (CC BY). The use, distribution or reproduction in other forums is permitted, provided the original author(s) or licensor are credited and that the original publication in this journal is cited, in accordance with accepted academic practice. No use, distribution or reproduction is permitted which does not comply with these terms. 